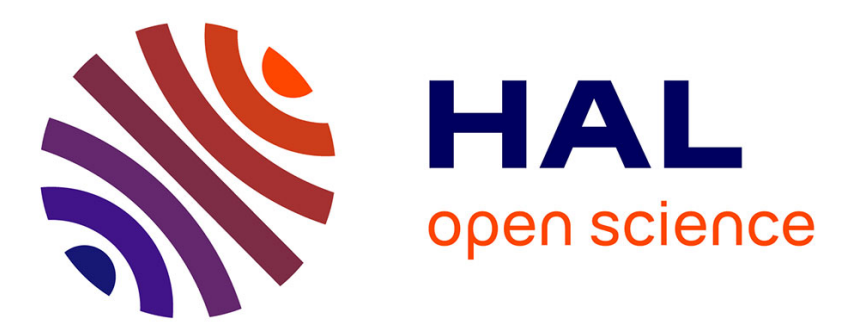

\title{
ENERGIES OF FORMATION OF POINT DEFECTS IN PERFECT AND DISLOCATED IONIC CRYSTALS
}

\author{
C. Woo, M. Puls, M. Norgett
}

\section{To cite this version:}

C. Woo, M. Puls, M. Norgett. ENERGIES OF FORMATION OF POINT DEFECTS IN PERFECT AND DISLOCATED IONIC CRYSTALS. Journal de Physique Colloques, 1976, 37 (C7), pp.C7-557C7-560. 10.1051/jphyscol:19767130 . jpa-00216854

\section{HAL Id: jpa-00216854 https://hal.science/jpa-00216854}

Submitted on 1 Jan 1976

HAL is a multi-disciplinary open access archive for the deposit and dissemination of scientific research documents, whether they are published or not. The documents may come from teaching and research institutions in France or abroad, or from public or private research centers.
L'archive ouverte pluridisciplinaire HAL, est destinée au dépôt et à la diffusion de documents scientifiques de niveau recherche, publiés ou non, émanant des établissements d'enseignement et de recherche français ou étrangers, des laboratoires publics ou privés. 


\title{
ENERGIES OF FORMATION OF POINT DEFECTS IN PERFECT AND DISLOCATED IONIC CRYSTALS
}

\author{
C. H. WOO, M. P. PULS and M. J. NORGETT (*) \\ Materials Science Branch, Atomic Energy of Canada Limited, Whiteshell \\ Nuclear Research Establishment, Pinawa, Manitoba, ROE 1LO, Canada
}

\begin{abstract}
Résumé. - Nous avons calculé les propriétés de noyau et les énergies de déformation d'une dislocation droite du type étroit dans $\mathrm{MgO}$. Le réseau de notre modèle comprend des ions à charge entière qui interagissent entre eux par les potentiels de Coulomb et de courte portée du type central. Le potentiel de Coulomb pour la dislocation a été évalué suivant la méthode originale de Madelung [1]. Pour tenir compte adéquatement de la polarisation des ions, nous avons employé le modèle à couche en allant ainsi au-delà du modèle d'ion ponctuel. Ce modèle à couche qui reflète la déformation des ions est consistant avec les propriétés élastiques de $\mathrm{MgO}$. La quantité de calcul considérable nécessaire pour l'obtention de la relaxation du réseau avec ce modèle complexe a été réduite grâce à l'emploi d'une zone autour de la dislocation qui répond d'une façon flexible à la relaxation explicite du noyau de la dislocation.

Ce modèle peut être étendu pour calculer l'interaction dislocation-défaut, par exemple pour le calcul de la relaxation d'un réseau contenant dislocation et des lacunes ou des interstitiels près du noyau de dislocation. Jusqu'ici nous avons évalué les énergies de liaison des lacunes cationiques et anioniques à divers sites dans la région de noyau. L'interaction peut être attractive ou répulsive suivant le site, et l'énergie varie entre $\sim 1 \mathrm{eV}$ et zéro.

Abstract. - A method previously developed for calculating the core configurations of simple dislocations has been extended to calculate dislocation-point defect interactions. Our lattice model represents the crystal by ions with integer charges interacting by Coulomb and short-range central potentials. The Coulomb potential for the dislocated lattice is computed using the original method of Madelung for calculating the potential of periodic strings of ions. Using the shell model, we have extended the method beyond the simplest case of unpolarisable ions (point-ion model) to allow a proper description of the ion polarization. The substantial calculation required to relax the dislocated lattice when a vacancy or interstitial is introduced is reduced by using a harmonic boundary region in which the ion positions are determined by assuming that this region acts as a dielectric continuum.

We have so far computed the binding energy of both anion and cation vacancies at various sites in the core. The interaction turns out to be attractive or repulsive at different sites and is of order $\sim 1 \mathrm{eV}$ at some sites but close to zero at others.
\end{abstract}

1. Introduction. - The configurations and energies of point defects and dislocations are important parameters in predicting the mechanical properties of solids. These quantities can be found from an atomistic calculation if suitable interaction potentials are known. Potential models for ionic crystals [1] give reliable defect energies in perfect crystals but have been only recently applied [2] in full detail to study dislocations. There have to date been only rather crude estimates [3] of the interaction of dislocation and point defects and our aim is a more rigorous and detailed estimate of such quantities. We consider specifically the $a / 2[110]$ edge dislocation in $\mathrm{MgO}$, calculating the energy of the dislocation with and without specific lattice vacancies in the core region. A comparison of the two energies with the appropriate vacancy formation energies in the perfect crystal gives the required vacancy binding energies.

(*) Theoretical Physics Division, AERE Harwell, Oxfordshire OX11 ORA, England.
2. Calculation. - We discuss interatomic potential models, then the nature of the calculation for the edge dislocation and finally give a brief description of the calculation for the further perturbation of the lattice when the point defect is introduced in the dislocation core.

2.1 Potential models. - We have used fully ionic point-ion models and breathing shell models for MgO. The central-force breathing shell model of Sangster [4] provides the simplest description of the elastic, dielectric and cohesive properties of $\mathrm{MgO}$. The breathing term is necessary to explain the large Cauchy violation in this material. A very similar model (called Model 1 by the authors) has already been used for point defect calculations in $\mathrm{MgO}$ by Catlow, Faux and Norgett [5] where the two models are compared. The same pair potentials can be used without explicitly including breathing deformation of the ions. Such models give correct lattice constant and shear moduli $C_{44}$ and $\frac{1}{2}\left(C_{11}-C_{12}\right)$. The lattice 
compressibility is ircorrect if the breathing term is omitted. Catlow et al. investigated an alternative shell model (called Model 2 by them) with pair potentials adjusted to give correct values for $C_{11}$ and $C_{12}$ separately. This model is not compatible with the breathing shell approach. The polarization in all such models is best described by the shell model with the anion spring constant and shell charge fitted to the dielectric constants and transverse-optic frequencies of $\mathrm{MgO}$. The cation is unpolarized. Any of the above models may also be employed as a point-ion model (without any ion polarization) when such effecis are unimportant. This greatly simplifies the computation.

2.2 Dislocation simulation. - The lattice is divided into two regions. The dislocation is initially defined by repositioning all the ions according to the simplest, anisotropic continuum solution for the elastic displacement field (Volterra solution). The core (region 1) is then relaxed explicitly calculating the forces from the given interionic potentials. The use of a rigid boundary with region 2 fixed during the relaxation of region 1 is realistic only if the core region is made very large. More efficient computation is possible with flexible boundaries, with region 2 adjusted to take account of the core relaxation.

We have tested two of the flexible boundary schemes in detail. Puls and Woo $[6,7]$ have shown that for ionic crystals, the «Flex II » method of Hoagland, Hirth and Gehlen [8] is more efficient than the alternative approach developed by Sinclair $[9,10]$.

The particular feature that distinguishes simulation in ionic crystals from that in other systems (which are usually simulated by short-range interatomic potentials) is the slowly converging Coulomb interaction. This latter Madelung contribution can be summed by methods that exploit the periodicity of the crystal. Madelung [11] himself originally calculated Madelung constants for perfect crystals by summing the contribution from infinite rows of charges of alternate sign. The same technique may be applied to the dislocation simulation, which utilizes the periodicity along the line of the dislocation edge. The method must be extended for application to the shell model when the polarization is represented by the relative displacement of core and shell charges. Each contribution must then be summed separately using the appropriate expressions given by Puls and Norgett [2].

2.3 CALCulations For VACANCIES NEAR DISLOCATION CORES. - The energy to remove an ion from the dislocation core to infinity is easily computed in the original dislocation formalism. The calculation of the further relaxation of the core about the point defect is more difficult, particularly the Coulomb part. Using the potential calculated for one-dimensional periodic charge arrays, we can estimate the interaction of a displaced charge with the original dislocated lattice. The dislocated crystal forms a reference system against which subsequent displacements are measured. For each displaced ion, there is thus a contribution to the potential from the reference lattice plus an interaction between pairs of displaced ions. This latter potential has the form of a dipole interaction. These dipole contributions are, firstly, from the interaction of the actual displaced charges and, secondly, from the vacated sites in the reference lattice. The present formalism is the same as that for the perfect crystal (see particularly Norgett $[12,13])$ except that the reference lattice is now the dislocated lattice and not the perfect crystal. Thus the Madelung contribution of the reference lattice must be found using a method utilising the appropriate symmetry.

The displacement dipoles decrease away from the point defect and the contribution of a complete spherical shell of dipoles rapidly approximates a continuum lattice polarization. This gives a constant potential within the spherical shell. Thus the energy of lattice polarization is explicitly calculated close to the defect, while further away, a harmonic approximation is used with a continuum estimate of the lattice displacement due to Mott and Littleton [14]. Again the treatment exactly parallels that for point defects developed in detail by Norgett $[12,13]$ for perfect crystals. The only modification required is the replacement of a lattice summation, expressing the longrange interaction of the polarization with the vacancy charge, by an equivalent integral.

3. Results. - The dislocated lattice forms the basic reference lattice for our calculations of the vacancy formation energy in the dislocation core region. Consequently, it is useful to summarise briefly some previous results $[2,6,7]$ for the dislocated lattice in $\mathrm{MgO}$. The results for the vacancy calculation then form the second part of our discussion.

3.1 Dislocation simulation. - It turns out, on geometrical grounds, that two symmetrical dislocation configurations are possible for an a/2 [110] edge dislocation in an fcc ionic crystal [15]. There

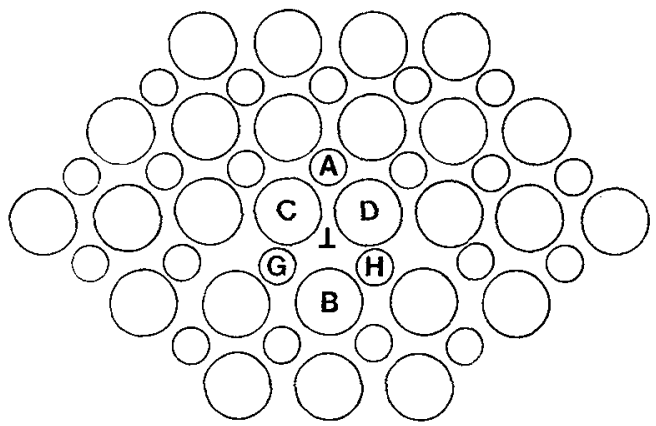

Fig. 1. - Core configuration of the stable symmetry type (designated type I) of an $a / 2$ [110] edge dislocation in $\mathrm{MgO}$. Labelled positions are those for which the vacancy energy of interaction with the dislocation have been calculated. 


\section{TABLE I}

Vacancy formation energies, $E_{\mathrm{F}}^{\mathrm{P}}$, in the perfect lattice

\begin{tabular}{|c|c|c|c|c|c|c|}
\hline \multirow[b]{2}{*}{ Vacancy Type } & \multirow[b]{2}{*}{$\begin{array}{c}\text { Model } \\
\text { Model 1 } \\
\text { potential }\end{array}$} & \multicolumn{2}{|c|}{ Radius in } & \multirow{2}{*}{$\begin{array}{c}\text { Atom } \\
\text { numbers } \\
\text { in Region } 1\end{array}$} & \multirow[b]{2}{*}{$\begin{array}{c}E_{\mathrm{F}}^{\mathrm{P}} \\
\mathrm{eV}\end{array}$} & \multirow[b]{2}{*}{ Reference } \\
\hline & & $\begin{array}{l}\text { Region } 1 \\
\text { Lattice uni }\end{array}$ & $\begin{array}{l}\text { Region } 2 \\
{ }^{*} \text { (shells) }\end{array}$ & & & \\
\hline- & - & \multicolumn{2}{|c|}{ - } & $\overline{32}$ & - & - \\
\hline \multirow[t]{7}{*}{ Cation } & \multirow[t]{4}{*}{ shell } & $2.0(4)$ & $6.0(41)$ & 33 & 24.22 & present work \\
\hline & & $3.0(9)$ & $6.0(41)$ & 123 & 23.88 & - - \\
\hline & & $4.0(15)$ & $6.0(41)$ & 257 & 23.83 & - - \\
\hline & & $3.0(9)$ & $5.0(32)$ & 123 & 23.82 & [5] \\
\hline & point & $2.0(4)$ & $6.0(41)$ & 33 & 24.36 & present work \\
\hline & ion & $3.0(9)$ & $6.0(41)$ & 123 & 24.09 & $-\quad-$ \\
\hline & & $4.0(15)$ & $6.0(41)$ & 257 & 24.06 & - \\
\hline \multirow[t]{3}{*}{ Anion } & shell & $4.0(15)$ & $6.0(41)$ & 257 & 24.68 & \multirow{3}{*}{$\begin{array}{l}\text { present work } \\
\text { [5] } \\
\text { present work }\end{array}$} \\
\hline & & $3.0(9)$ & $5.0(32)$ & 123 & 24.70 & \\
\hline & $\begin{array}{c}\text { point } \\
\text { ion }\end{array}$ & $4.0(15)$ & $6.0(41)$ & 257 & 24.81 & \\
\hline
\end{tabular}

(*) Lattice units measure distances in units of the interionic distance $=2.106 \AA$ in $\mathrm{MgO}$.

is then a question which of the two, or both, represent stable configurations. The rigid boundary and Flex-II calculations (for both the point-ion and shell models) yielded the equivocal result that when using Model 1 potential, symmetry I (shown in Fig. 1) is the stable configuration while when using Model 2 potential, symmetry II is the stable configuration. However, using Flex-II with the breathing shell model we found that for both Model 1 and Sangster's potential, symmetry $I$ is the stable configuration. Since the latter model is at least completely consistent with the elastic properties of $\mathrm{MgO}$, we are led to conclude that the results derived with the Model 2 potential are probably incorrect and that symmetry $I$ is, in fact, the true stable configuration.

If we compare the calculated core configuration, the Peierls stress and volume of expansion [7], the results obtained with Model 1 and the analogous Sangster potential are very similar. Except for the Peierls stress, there is also little change as we substitute the more sophisticated shell and breathing shell models for the point-ion model. The improved treatment of the ion polarization and deformation has little effect although the calculations of Puls and Norgett [2] show substantial variations in the electronic polarization of the $\mathrm{O}^{2-}$ ions at different locations about the core. The need for a correct description of the lattice polarization is, however, of paramount importance in calculating the energies of charged defects $[1,5]$. This requires that our initial dislocation calculations should be extended at least to include the shell model.

3.2 ENERGIES OF FORMATION FOR VACANCIES NEAR DISLOCATION CORES. - The present method of calcu- lation has been checked, first by calculating the anion and cation vacancy formation energies in a perfect lattice of $\mathrm{MgO}$ using the Model 1 potential. The results are summarized in table 1 for the shell model and compared with the corresponding shell model results for $\mathrm{MgO}$ by Catlow, Faux and Norgett [5] using Hades $\left({ }^{1}\right)$. The excellent agreement verifies the accuracy and correctness of the method presented in this paper. We can thus have confidence in the results obtained for the dislocated lattice vacancy formation energies. In addition, it is evident from table I and the results of Catlow et al. [5] that to achieve good accuracy, region 1 must have a radius of about 4.0 lattice units $\left({ }^{2}\right)$ (or 15 shells) and a region 2 radius of 6.0 lattice units (or 41 shells). Consequently we have calculated $E_{F}^{D}$ for the dislocated lattice using these region sizes. However our investigation of the optimum region sizes has been by no means exhaustive and it may be that a smaller region size will suffice.

We have obtained $E_{\mathrm{F}}^{\mathrm{D}}$ values for a vacancy situated at the A, B, C, D, G and $\mathrm{H}$ positions near the $a / 2$ [110] edge dislocation's center (these positions are shown in Fig. 1). These results are summarized in table II, together with the corresponding values for the interaction energy, $E_{\text {int }}$. The numerical accuracy of the results given in table $I I$ is estimated to be about $\pm 0.1 \mathrm{eV}$.

(1) It is interesting to note that the vacancy formation energies obtained with the point-ion model differ by only a small amount $(\sim 0.2 \mathrm{eV})$ from those obtained with the shell model. This is a somewhat surprising result and is apparently a consequence of the fact that for $\mathrm{MgO} \varepsilon_{\infty}$ is so low compared to $\varepsilon_{0}$.

(2) Lattice units measure distances in units of the interionic distance $\equiv 2.106 \AA$ in $\mathrm{MgO}$. 


\section{TABLE II}

Vacancy formation $\left(E_{\mathrm{F}}^{\mathrm{O}}\right)$ and interaction energies $\left(E_{\mathrm{int}}\right)$ in the dislocated lattice. The vacancy is located at positions (shown in figure 1) near the center of the stable symmetry configuration of an a/2 [110] edge dislocation

\begin{tabular}{|c|c|c|c|c|c|}
\hline Model & $\begin{array}{c}\text { Vacancy } \\
\text { type }\end{array}$ & Position & $\begin{array}{l}\text { Atom numbers } \\
\text { in region } 1(*)\end{array}$ & $E_{\mathrm{F}}^{\mathrm{D}}$ & $\begin{array}{l}E_{\text {int }}(* *) \\
\mathrm{eV} \\
-\end{array}$ \\
\hline \multirow[t]{5}{*}{ Shell } & cation & A & 277 & 24.99 & 1.14 \\
\hline & anion & A & 277 & 25.84 & 1.16 \\
\hline & anion & $\mathbf{B}$ & 273 & 24.59 & -0.10 \\
\hline & anion & C, D & 281 & 23.59 & -1.09 \\
\hline & cation & $\mathrm{G}, \mathrm{H}$ & 280 & 23.94 & -0.11 \\
\hline \multirow{4}{*}{$\begin{array}{l}\text { Point } \\
\text { ion }\end{array}$} & cation & A & 277 & 24.84 & 0.77 \\
\hline & anion & B & 273 & 24.23 & -0.58 \\
\hline & anion & C, D & 281 & 23.41 & -1.40 \\
\hline & cation & $\mathbf{G}, \mathbf{H}$ & 280 & 23.84 & -0.22 \\
\hline
\end{tabular}

(*) All calculations were done with a region 1 radius of 4.1 lattice units and a region 2 radius of 6.1 lattice units.

(**) $E_{\text {int }}=E_{\mathrm{F}}^{\mathrm{D}}-E_{\mathrm{F}}^{\mathrm{P}}$.
For the « $A$ » position we have calculated both the anion and the cation formation energies. These values differ by about $1 \mathrm{eV}$, as for the perfect lattice. Hence, $E_{\text {int }}$ is approximately the same for both ions. We may expect a similar trend to apply to the other positions. Table II shows that the interaction is repulsive (positive energy) at the «A» position while it is attractive (negative) for all the others. Note, in particular, that for a vacancy at positions $B, G$ and $H$ there is a negligible interaction energy with the dislocation. Finally, comparison between the pointion and shell model results shows that the electronic polarization contributes a positive energy to $E_{\text {int }}$ which, except for positions $G$ and $H$, is roughly about $0.3 \mathrm{eV}$. This is close to the energy difference between the point-ion and shell model values for the perfect lattice formation energies and suggests that a vacancy in a dislocated lattice causes a smaller amount of polarization than in a perfect crystal.

\section{References}

[1] Lidiard, A. B. and Norgetr, M. J., in Computational Solid State Physics. Ed. by Herman F., Dalton, N. W. and Koehler, T. R. (Plenum Press) 1972, p. 385.

[2] Puls, M. P. and Norgetr, M. J., J. Appl. Phys. 47 (1976) 466.

[3] Bassani, F. and Thomson, R., Phys. Rev. 102 (1956) 1264.

[4] SANGster, M. J. L., J. Phys. \& Chem. Solids 34 (1973) 355.

[5] Catlow, C. R. A., Faux, I. D. and Norgett, M. J., J. Phys. C 9 (1976) 419.

[6] Puls, M. P. and Woo, C. H., AECL Report No. AECL 5238 (1975).

[7] Woo, C. H. and Purs, M. P., Phil. Mag. (in press).
[8] Hoagland, R. G., Hirth, J. P. and Gehlen, P. C., Phil. Mag. 34 (1976) 413.

[9] Sinclair, J. E., J. Appl. Phys. 42 (1971) 5321.

[10] Sinclair, J. E., Phil. Mag. 31 (1975) 647.

[11] Madelung, E., Phys. Z. 19 (1918) 524.

[12] NoRgetT, M. J., AERE Harwell Report No. AERER7650 (1974).

[13] Norgett, M. J., AERE Harwell Report No. AERER7780 (1974).

[14] Mott, N. F. and Littleton, M. J., Trans. Farad. Soc. 34 (1938) 485.

[15] HirTh, J. P. and Lothe, L., Theory of Dislocations New York: McGraw-Hill (1968) p. 376. 